\title{
DAMPING MODELS FOR SHEAR-DEFORMABLE BEAM WITH APPLICATIONS TO SPACECRAFT WIRING HARNESS
}

George A. Lesieutre and Jeffery L. Kauffman

Pennsylvania State University

408 Old Main

University Park, PA 16802

28 Oct 2014

Final Report

APPROVED FOR PUBLIC RELEASE; DISTRIBUTION IS UNLIMITED.

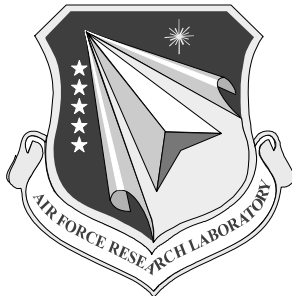

AIR FORCE RESEARCH LABORATORY Space Vehicles Directorate 3550 Aberdeen Ave SE AIR FORCE MATERIEL COMMAND KIRTLAND AIR FORCE BASE, NM 87117-5776 


\section{DTIC COPY NOTICE AND SIGNATURE PAGE}

Using Government drawings, specifications, or other data included in this document for any purpose other than Government procurement does not in any way obligate the U.S. Government. The fact that the Government formulated or supplied the drawings, specifications, or other data does not license the holder or any other person or corporation; or convey any rights or permission to manufacture, use, or sell any patented invention that may relate to them.

This report is the result of contracted fundamental research deemed exempt from public affairs security and policy review in accordance with SAF/AQR memorandum dated 10 Dec 08 and AFRL/CA policy clarification memorandum dated 16 Jan 09. This report is available to the general public, including foreign nationals. Copies may be obtained from the Defense Technical Information Center (DTIC) (http://www.dtic.mil).

\section{AFRL-RV-PS-TR-2014-0189 HAS BEEN REVIEWED AND IS APPROVED FOR PUBLICATION IN ACCORDANCE WITH ASSIGNED DISTRIBUTION STATEMENT.}

//SIGNED//

DEREK DOYLE

Program Manager

//SIGNED//

BENJAMIN M. COOK, Lt Col, USAF

Deputy Chief, Spacecraft Technology Division

Space Vehicles Directorate
//SIGNED//

PAUL HAUSGEN

Technical Advisor, Spacecraft Component Technology Branch

This report is published in the interest of scientific and technical information exchange, and its publication does not constitute the Government's approval or disapproval of its ideas or findings. 


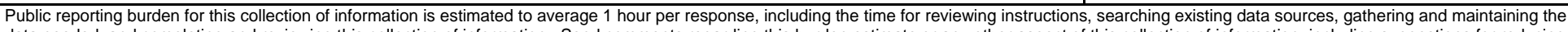

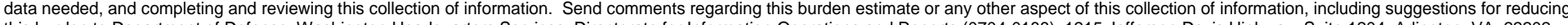

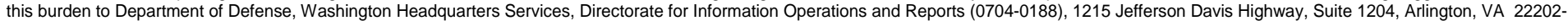

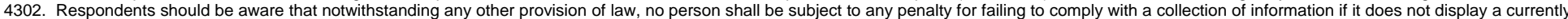
valid OMB control number. PLEASE DO NOT RETURN YOUR FORM TO THE ABOVE ADDRESS.

\begin{tabular}{l|l} 
1. REPORT DATE $(D D-M M-Y Y)$ & 2. REPORT TYPE
\end{tabular}

28-10-2014

4. TITLE AND SUBTITLE

Damping Models for Shear-Deformable Beam with Applications to Spacecraft Wiring

Harness

Final Report
3. DATES COVERED (From - To)

15 Feb 2011 - 15 Feb 2012

5a. CONTRACT NUMBER

FA9453-12-1-0137

5b. GRANT NUMBER

5c. PROGRAM ELEMENT NUMBER

$61102 \mathrm{~F}$

5d. PROJECT NUMBER

2302

5e. TASK NUMBER

PPM00018410

5f. WORK UNIT NUMBER

8. PERFORMING ORGANIZATION REPORT NUMBER

Pennsylvania State University

408 Old Main

University Park, PA 16802

\section{SPONSORING I MONITORING AGENCY NAME(S) AND ADDRESS(ES)}

Air Force Research Laboratory

Space Vehicles Directorate

3550 Aberdeen Ave., SE

Kirtland AFB, NM 87117-5776

\section{DISTRIBUTION I AVAILABILITY STATEMENT}

Approved for public release; distribution is unlimited.

\section{SPONSOR/MONITOR'S ACRONYM(S) \\ AFRL/RVSV}

11. SPONSOR/MONITOR'S REPORT NUMBER(S)

AFRL-RV-PS-TR-2014-0189

\section{SUPPLEMENTARY NOTES}

\section{ABSTRACT}

Cabling attached to a spacecraft bus structure can represent a significant fraction of the dry mass. While current models can accurately predict vibration frequencies of the coupled system, typical damping models are inadequate. Instead, a viscous damping model that produces approximately frequency-independent modal damping in Euler-Bernoulli and shear beams is considered. The relevant viscous damping terms are extended and modified for application to Timoshenko beams. The inclusion of rotary inertia does add some frequencydependence; however, careful selection of damping coefficients can produce a large range of approximately frequency-independent modal damping. This effort will extend recent basic research to explore damping models for use with shear-deformable beams, and will begin to address fundamental physical damping mechanisms and potential non-linear dissipative sources in spacecraft cables. The desired outcome is a time domain beam model that represents with physical consistency the damping behavior of wiring harnesses. The emphasis in this project will be on the extension of the shear-beam damping model to the Timoshenko beam, a beam model that includes the effects of rotatory inertia. Including this sometimes-significant effect is likely to change the damping behavior at higher mode numbers.

\section{SUBJECT TERMS}

cable dampening, damping models, shear-deformable beams

\begin{tabular}{|c|c|c|c|c|c|}
\hline \multicolumn{3}{|c|}{ 16. SECURITY CLASSIFICATION OF: } & \multirow{2}{*}{$\begin{array}{l}\text { 17. LIMITATION } \\
\text { OF ABSTRACT } \\
\text { Unlimited }\end{array}$} & \multirow{2}{*}{$\begin{array}{l}\text { 18. NUMBER } \\
\text { OF PAGES } \\
\qquad 24\end{array}$} & \multirow{2}{*}{$\begin{array}{l}\text { 19a. NAME OF RESPONSIBLE PERSON } \\
\text { Derek Doyle } \\
\text { 19b. TELEPHONE NUMBER (include area } \\
\text { code) }\end{array}$} \\
\hline $\begin{array}{l}\text { a. REPORT } \\
\text { Unclassified }\end{array}$ & $\begin{array}{l}\text { b. ABSTRACT } \\
\text { Unclassified }\end{array}$ & $\begin{array}{l}\text { c. THIS PAGE } \\
\text { Unclassified }\end{array}$ & & & \\
\hline
\end{tabular}


(This page intentionally left blank)

Approved for Public Release; distribution is unlimited. 


\section{TABLE OF CONTENTS}

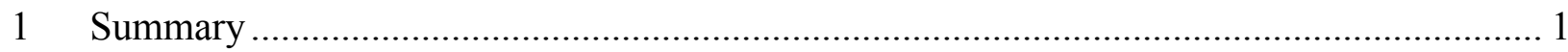

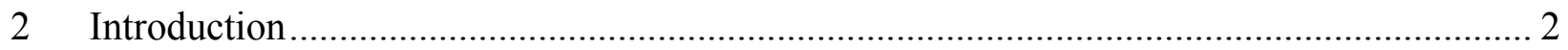

3 Methods, Assumptions, and Procedures .................................................................... 3

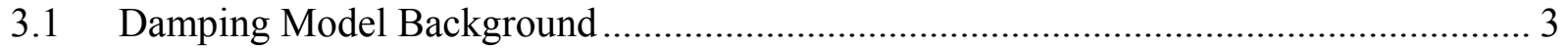

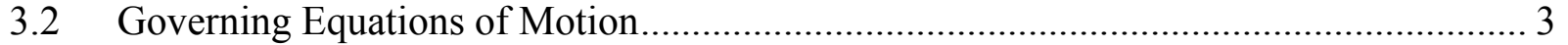

3.3 Finite Element Model.................................................................................. 5

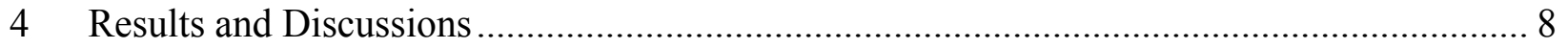

4.1 Modal Damping Values for Several Viscous Damping Models .................................. 8

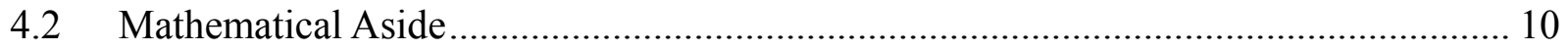

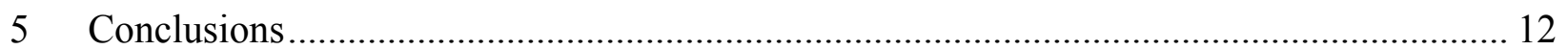

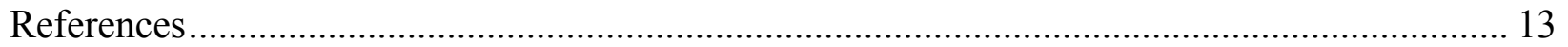

Approved for Public Release. distribution is unlimited. 


\section{LIST OF FIGURES}

Figure 1. Modal damping for several viscous damping models with small shear deformation and rotary inertia effects.......................................................................... 9

Figure 2. Modal damping for several viscous damping models with large shear deformation and

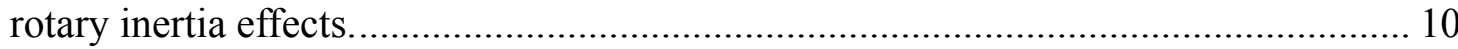

Approved for Public Release. distribution is unlimited. 


\section{ACKNOWLEDGMENTS AND DISCLAIMER}

This material is based on research sponsored by Air Force Research Laboratory under agreement number FA9453-12-1-0137. The U.S. Government is authorized to reproduce and distribute reprints for Governmental purposes notwithstanding any copyright notation thereon.

The views and conclusions contained herein are those of the authors and should not be interpreted as necessarily representing the official policies or endorsements, either expressed or implied, of Air Force Research Laboratory or the U.S. Government.

The authors thank Derek Doyle as well as Emil Ardelean, Vit Babuska, Douglas Coombs, and James Goodding for a thorough explanation of previous modeling approaches and valuable and insightful feedback. 
This Page Intentionally Left Blank

Approved for Public Release. distribution is unlimited. 


\section{SUMMARY}

Power and data cabling are attached to a spacecraft bus structure at many points and can account for a significant fraction of a spacecraft's dry mass. This combination leads to coupled spacecraft and cable dynamics that require a model to predict the effects of this interaction. While current models can accurately predict vibration frequencies, typical proportional damping models are inadequate. Instead, a viscous damping model that produces approximately frequencyindependent modal damping in Euler-Bernoulli and shear beams is considered. The relevant viscous damping terms (as well as those commonly employed in proportional damping approaches) are extended and modified for application to Timoshenko beams. The inclusion of rotary inertia does add some frequency-dependence; however, careful selection of damping coefficients can produce a large range of approximately frequency-independent modal damping.

This paper will specifically consider a careful selection of coefficients for the rotationbased viscous damping models to provide modal damping that is approximately independent of modal frequency, at least over a significant range of vibration modes. Guidance in this parameter selection and the resulting modal damping will be presented for several combinations of canonical boundary conditions, including simply-supported and clamped-clamped Timoshenko beams. Furthermore, a series expansion of the mathematical form of "square-root" damping will be explored to provide an increased range of frequency-independent modal damping and a corresponding explanation of the underlying dissipative physical mechanisms. 


\section{INTRODUCTION}

Recent advances in spacecraft observation, data handling, and vibration control capabilities and requirements have led to large amounts of power and data cabling on spacecraft. Coupled with materials advances that lead to structural materials with decreased density, these cables can account for a large proportion of the spacecraft mass. In fact, this cabling mass ratio can reach $30 \%$ (of the dry mass) for some spacecraft [1,2].The cabling is attached to the spacecraft structure at a large number of points, leading to coupled spacecraft dynamics. While this coupling is not typically modeled in the design process, it is commonly observed during ground system-level testing. In most cases, this testing provides the data required to model the spacecraft structure and cabling interaction; however, an accurate model during the initial design phases is significantly more desirable.

Spacecraft cabling typically consists of wrapped, stitched, and twisted wires, so previous research toward such a model treated the cabling as shear beams with effective parameters [1-4]. While individual cable bundles can be long and slender, they are tightly secured at numerous tie down points. As such, previous research treated each bundle as a series of short beams with a free span between those tie down points. Initial research efforts employed structural damping through a loss factor in a NASTRAN finite element model. While providing adequate results for frequency-domain modeling, a time-domain model was desired. Furthermore, experimental tests indicated the cable bundles displayed modal damping that was approximately constant across a range of vibration modes. As such, a viscous damping model developed by Lesieutre that produced frequency-independent modal damping in Euler-Bernoulli beams was extended to and modified for the shear beam $[5,6]$. This model yielded modal damping that was approximately frequency-independent and agreed well with experimental data. On that basis, this paper will further extend and modify the model for application to Timoshenko beams by including the effects of rotary inertia. 


\section{METHODS, ASSUMPTIONS, AND PROCEDURES}

\subsection{Damping Model Background}

There are several common approaches to incorporate a damping model for Timoshenko beams. Perhaps the most common is the structural damping model. Taken to its extreme, it accommodates a complex form for every parameter of the system. As an example, Lunden and Akesson showed this approach results in 14 damping terms, although simultaneously pointing out that in practical terms all but a few of these terms would be identically zero [7]. More typical is a complex form of the Young's and shear moduli, resulting in at most two damping terms [711]. While these methods are ill-suited for time-domain modeling, they can provide valuable insight into potential damping models.

The second common approach is through the inclusion of proportional damping terms. Here damping terms result as some combination of terms proportional to the mass and stiffness terms [12-19]. This technique is mathematically convenient; however, it fails to provide modal damping that is physically realistic. Indeed, a high degree of frequency-dependence is seen with proportional damping, whether formulated for an Euler-Bernoulli or Timoshenko beam. Lesieutre provided a solution for this unrealistic behavior, developing a "rotation-based" (also called "geometric-based") viscous damping model that results in approximately frequencyindependent modal damping for Euler-Bernoulli beams [5]. Subsequent research extended and modified this model for application to shear beams; that model serves as the starting point for this study of frequency-independent modal damping for Timoshenko beams [6].

\subsection{Governing Equations of Motion}

Including rotary inertia and_rst-order transverse shear deformation, the governing equations of motion for a Timoshenko beam without damping and subject to transverse loading are

$$
\begin{aligned}
-\frac{\partial}{\partial t}\left(\rho A \frac{\partial w}{\partial t}\right)+\frac{\partial}{\partial x}\left[\kappa A G\left(\frac{\partial w}{\partial x}-\varphi\right)\right] & =-q \\
-\frac{\partial}{\partial t}\left(\rho I \frac{\partial \varphi}{\partial t}\right)+\frac{\partial}{\partial x}\left(E I \frac{\partial \varphi}{\partial x}\right)+\kappa A G\left(\frac{\partial w}{\partial x}-\varphi\right) & =0
\end{aligned}
$$

where the shear deformation is described by

$$
\beta=\frac{\partial w}{\partial x}-\varphi
$$


Note that this approach results in three coordinates to describe the beam, yet only two are independent. The following approach continues in terms of the beam displacement $(\mathrm{w})$ and the slope of the beam centerline associated with bending $(\varphi)$ only. Analysis in terms of the shear deformation $(\beta)$ yields identical results.

For simplicity, restrict the beam to have constant properties along its length. Denoting spatial partial derivatives as ( )' and temporal partial derivatives as ()$\left.^{(}\right)$, the equations of motion are

$$
\begin{aligned}
-\rho A \ddot{w}+\kappa A G\left(w^{\prime \prime}-\varphi^{\prime}\right) & =-q \\
-\rho I \ddot{\varphi}+E I \varphi^{\prime \prime}+\kappa A G\left(w^{\prime}-\varphi\right) & =0
\end{aligned}
$$

These equations of motion can be written in terms of a single coordinate; however, the current effort will incorporate damping terms that precludes such a simplification.

This initial analysis treats a simply-supported Timoshenko beam; the associated boundary conditions require both the displacement and bending moment be zero at the beam endpoints:

$$
w(0, t)=w(L, t)=E I \varphi^{\prime}(0, t)=E I \varphi^{\prime}(L, t)=0
$$

Subsequent analysis may consider alternative boundary conditions. For example, a clampedclamped Timoshenko beam requires the displacement and slope associated with bending to be zero at the beam endpoints:

$$
w(0, t)=w(L, t)=\varphi(0, t)=\varphi(L, t)=0
$$

\section{Viscous Damping Models}

Several viscous damping models are considered here. They can largely be classified as motion-, rotation- (or geometric-), and strain-based models. Two motion-based terms are proportional to the inertia of the beam and represent loads that oppose the beam velocity $\left(\alpha_{\mathrm{Mw}}\right)$ and rotation rate $\left(\alpha_{\mathrm{M} \varphi}\right)$. Two strain-based terms are proportional to the rigidity of the beam and represent loads that oppose the temporal rates of change of beam centerline curvature $\left(\alpha_{\mathrm{K} \varphi}\right)$ and shear curvature $\left(\alpha_{\kappa \beta}\right)$. Finally, rotation- (geometric-) based terms are associated with loads that oppose the temporal rates of change of the beam centerline angle $\left(\alpha_{\varphi}\right)$ and shear angle $\left(\alpha_{\beta}\right)$. The resulting equations of motion are

$$
\begin{aligned}
-\rho A \ddot{w}+\kappa A G\left(w^{\prime \prime}-\varphi^{\prime}\right) & =-q+\alpha_{M w} \dot{w}-\alpha_{K \beta} \dot{\beta}^{\prime}-\alpha_{\varphi} \dot{\varphi}^{\prime} \\
-\rho I \ddot{\varphi}+E I \varphi^{\prime \prime}+\kappa A G\left(w^{\prime}-\varphi\right) & =-\alpha_{E I} \dot{\varphi}^{\prime \prime}+\alpha_{M \varphi} \dot{\varphi}-\alpha_{\beta} \dot{\beta}
\end{aligned}
$$


Note that due to the use of all three coordinates, some of these damping terms will necessarily overlap; in fact, some terms may actually offset the damping introduced by other terms. For example, the equations of motion were presented in terms of the displacement (w) and slope of the beam centerline associated with bending $(\varphi)$ only; substituting Equation (2) into Equation (6) yields:

$$
\begin{aligned}
-\rho A \ddot{w}+\kappa A G\left(w^{\prime \prime}-\varphi^{\prime}\right) & =-q+\alpha_{M w} \dot{w}-\alpha_{K \beta} \dot{w}^{\prime \prime}-\left(\alpha_{\varphi}-\alpha_{K \beta}\right) \dot{\varphi}^{\prime} \\
-\rho I \ddot{\varphi}+E I \varphi^{\prime \prime}+\kappa A G\left(w^{\prime}-\varphi\right) & =-\alpha_{E I} \dot{\varphi}^{\prime \prime}+\left(\alpha_{M \varphi}+\alpha_{\beta}\right) \dot{\varphi}-\alpha_{\beta} \dot{w}^{\prime}
\end{aligned}
$$

In the first equation, the $\dot{\varphi}^{\prime}$ term is multiplied by the difference between $\alpha_{\varphi}$ and $\alpha_{\kappa} \beta$. That is, independent selection of positive damping coefficients can result in negative damping. As such, the damping coefficients are coupled and must be selected together, just as the beam displacement $(w)$, centerline bending angle $(\varphi)$, and shear deformation $(\beta)$ are coupled and must be analyzed jointly.

\subsection{Finite Element Model}

Unlike the Euler-Bernoulli and shear beams, the damped Timoshenko beam equations of motion are, in general, not readily treated analytically through consideration of modal motion. While some limited combinations of viscous damping models and boundary conditions admit such an approach, numerical techniques are required for a more general analysis. As such, a finite element formulation is developed from the weak form of the damped equations of motion.

\section{Discretization of Equation of Motion with Damping Terms}

Beginning with a weak formulation of the unforced Timoshenko beam equations of motion, application of the Galerkin method of weighted residuals and integration by parts results in

$$
\begin{gathered}
\int_{0}^{L}\left(w \rho A \ddot{w}+w^{\prime} \kappa A G w^{\prime}+w \kappa A G \varphi^{\prime}+w \alpha_{M w} \dot{w}+w^{\prime} \alpha_{K \beta} \dot{w}^{\prime}+w \alpha_{K \beta} \dot{\varphi}^{\prime}-w \alpha_{\varphi} \dot{\varphi}^{\prime}\right) \mathrm{d} x=0 \\
\int_{0}^{L}\left(\varphi \rho I \ddot{\varphi}+\varphi^{\prime} E I \varphi^{\prime}-\varphi \kappa A G w^{\prime}+\varphi \kappa A G \varphi+\varphi^{\prime} \alpha_{K \varphi} \dot{\varphi}^{\prime}-\varphi \alpha_{M \varphi} \dot{\varphi}-\varphi \alpha_{\beta} \dot{w}^{\prime}+\varphi \alpha_{\beta} \dot{\varphi}\right) \mathrm{d} x=0
\end{gathered}
$$

The next step is the introduction of a set of shape functions for the coordinates, $w$ and $\varphi$, taking care to avoid the shear locking problem. Several such approaches exist; the solution employed here is to interpolate the displacement, $w$, using cubic shape functions and the centerline slope associated with bending, $\varphi$, using quadratic shape functions [20]. The coordinates can thus be written in terms of the shape functions 


$$
\begin{aligned}
w & =\left[N_{w}\right]\{\delta\} \\
\varphi & =\left[N_{\varphi}\right]\{\delta\}
\end{aligned}
$$

where

$$
\{\delta\}=\left[\begin{array}{llll}
w_{A} & \varphi_{A} & w_{B} & \varphi_{B}
\end{array}\right]^{t}
$$

The shape functions are

$$
\left[N_{w}\right]=\left\{\begin{array}{c}
\frac{1}{1+\phi}\left(2\left(\frac{x}{L_{\mathrm{el}}}\right)^{3}-3\left(\frac{x}{L_{\mathrm{el}}}\right)^{2}-\phi \frac{x}{L_{\mathrm{el}}}+1+\phi\right) \\
\frac{L_{\mathrm{el}}}{1+\phi}\left(\left(\frac{x}{L_{\mathrm{el}}}\right)^{3}-\left(2+\frac{\phi}{2}\right)\left(\frac{x}{L_{\mathrm{el}}}\right)^{2}+\left(1+\frac{\phi}{2}\right) \frac{x}{L_{\mathrm{el}}}\right) \\
-\frac{1}{1_{\phi}}\left(2\left(\frac{x}{L_{\mathrm{el}}}\right)^{3}-3\left(\frac{x}{L_{\mathrm{el}}}\right)^{2}-\phi \frac{x}{L_{\mathrm{el}}}\right) \\
\frac{L_{\mathrm{el}}}{1+\phi}\left(\left(\frac{x}{L_{\mathrm{el}}}\right)^{3}-\left(1-\frac{\phi}{2}\right)\left(\frac{x}{L_{\mathrm{el}}}\right)^{2}-\frac{\phi}{2} \frac{x}{L_{\mathrm{el}}}\right)
\end{array}\right\}
$$

Where $\phi$ is an elemental shear stiffness parameter:

$$
\phi=\frac{E I}{\kappa A G} \frac{12}{L_{\mathrm{el}}^{2}}
$$


Inserting these shape functions in Equation (8) ultimately leads to the mass, damping, and stiffness matrices for each element. The elemental mass matrix comes from terms involving the second time derivative of the displacements and rotations:

$$
[M]=\int_{0}^{L_{\mathrm{el}}} \rho A\left(\left[N_{w}\right]^{t}\left[N_{w}\right]+R\left[N_{\varphi}\right]^{t}\left[N_{\varphi}\right]\right) \mathrm{d} x
$$

where $R=\rho I / \rho A$ is a parameter describing the effect of rotary inertia.

The elemental stiffness matrix comes from terms involving no time derivatives:

$$
[K]=\int_{0}^{L_{\mathrm{el}}} E I\left(\left[N_{\varphi}^{\prime}\right]^{t}\left[N_{\varphi}^{\prime}\right]+S\left(\left[N_{w}^{\prime}\right]^{t}\left[N_{w}^{\prime}\right]+\left[N_{w}\right]^{t}\left[N_{\varphi}^{\prime}\right]-\left[N_{\varphi}\right]^{t}\left[N_{w}^{\prime}\right]+\left[N_{\varphi}\right]^{t}\left[N_{\varphi}\right]\right)\right) \mathrm{d} x
$$

where $S=k A G / E I$ is a parameter describing the effect of transverse shear. Note that, in contrast to $R$, large values of $S$ indicate that transverse shear can largely be neglected (since the beam is very stiff in shear compared to bending).

Finally, the elemental damping matrix comes from terms involving a single time derivative:

$$
\begin{aligned}
{[C]=\int_{0}^{L_{\mathrm{el}}}(} & \alpha_{M w}\left[N_{w}\right]^{t}\left[N_{w}\right]-\alpha_{M \varphi}\left[N_{\varphi}\right]^{t}\left[N_{\varphi}\right]+\alpha_{K \varphi}\left[N_{\varphi}^{\prime}\right]^{t}\left[N_{\varphi}^{\prime}\right] \\
& \left.+\alpha_{K \beta}\left[N_{w}^{\prime}\right]^{t}\left[N_{w}^{\prime}\right]-\alpha_{\varphi}\left[N_{w}\right]^{t}\left[N_{\varphi}^{\prime}\right]-\alpha_{\beta}\left[N_{\varphi}\right]^{t}\left[N_{w}^{\prime}\right]+\alpha_{\beta}\left[N_{\varphi}\right]^{t}\left[N_{\varphi}\right]\right) \mathrm{d} x
\end{aligned}
$$




\section{RESULTS AND DISCUSSIONS}

\subsection{Modal Damping Values for Several Viscous Damping Models}

The key result is that the rotation-based viscous damping models can provide modal damping values with less frequency dependence than those produced by common motion- and strain-based viscous damping models. However, the effects of shear deformation and rotary inertia re-introduce the frequency-dependence commonly seen with motion- and strain-based models, although to a lesser extent.

Figure 1 shows the modal damping values produced by the various damping models when the shear deformation and rotary inertia effects are present but small. As is expected from the analysis of Euler-Bernoulli beams, the motion-based model provides modal damping that very rapidly decreases with mode number, while the damping values produced by the strainbased model increase unrealistically with mode number. The two rotation-based models as developed for the shear beam provide modal damping that is approximately constant with mode number. Note that the finite element analysis used 50 elements, so numerical artifacts may have some effect for the higher mode numbers. 


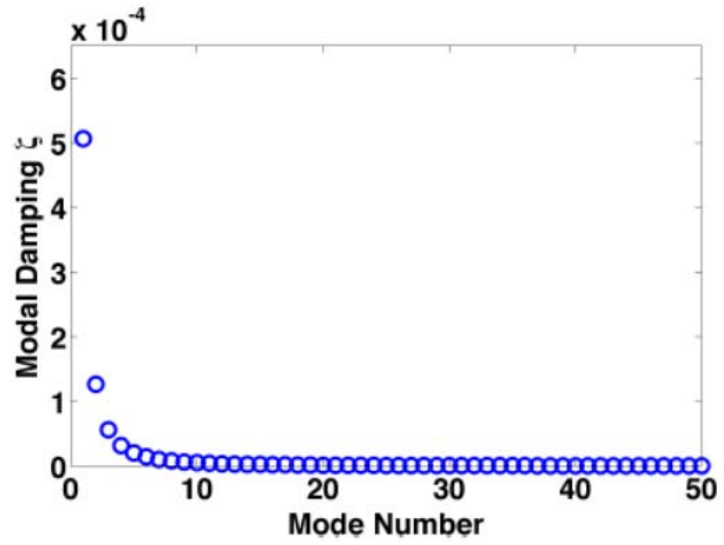

(a) Motion-based model.

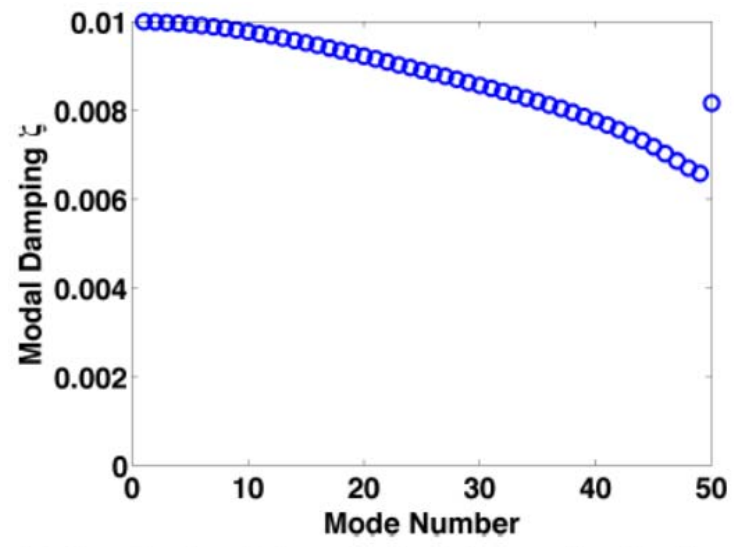

(c) Rotation-based (associated with centerline bending angle).

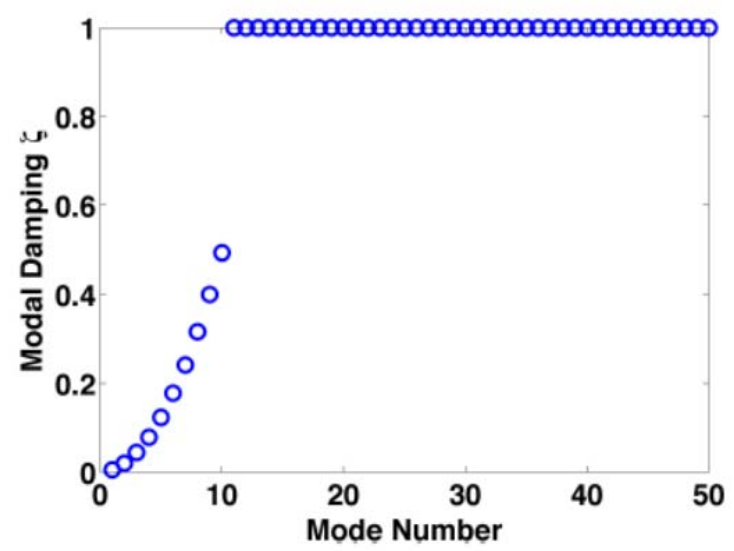

(b) Strain-based model.

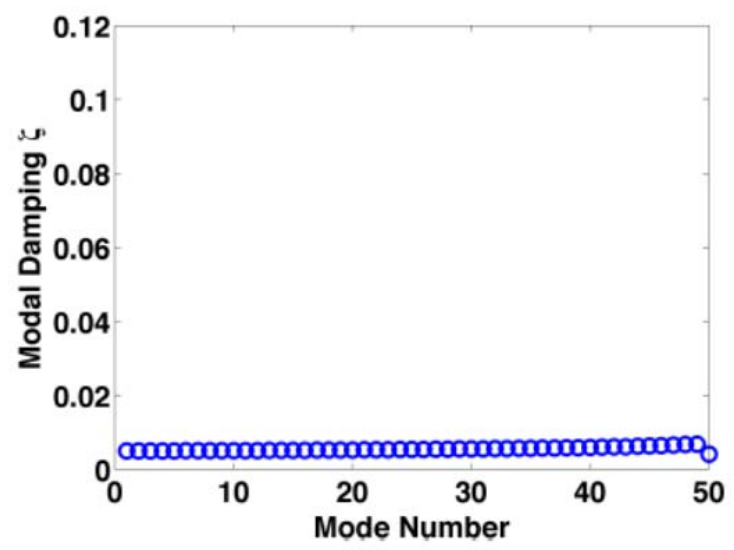

(d) Rotation-based (associated with shear angle).

Figure 1 Modal damping for several viscous damping models with small shear deformation and rotary inertia effects.

Figure 2 shows the modal damping values produced when the shear deformation and rotary inertia effects are significant (well beyond that typically observed in spacecraft wiring harnesses). Again, the motion-based model provides modal damping that very rapidly decreases with mode number, while the modal damping produced by the strain-based model increases very rapidly with mode number. In this case, the two rotation based models now also provide modal damping that decreases or increases with mode number, though not nearly as quickly as that of the motion- and strain-based models. As such, a combination of these models (with some modification) is expected to provide approximately frequency-independent modal damping over a significant range of vibration modes. Certainly motion- and strain-based viscous damping models can also be modified to provide approximate frequency-independence over a small range of modes; similar use of the rotation-based damping models should significantly extend that range.

Finally, note that Figures 2(c) and 2(d) show significant damping for only some of the modes. Figure 2(d) makes this point most clearly, with approximately linearly increasing modal damping for one set of modes and approximately constant (but zero!) modal damping for another 
set of modes. In fact, the modes with approximately linearly increasing modal damping have deflection shapes that primarily reflect shear deformation. Conversely, the modes with nearly zero modal damping exhibit deflection shapes that primarily involve bending. Indeed, this particular model involves only damping associated with the shear angle, so it makes sense that modal damping is significant in those modes most heavily associated with shear deformation. This behavior also provides insight into the damping model effects and may further guide the selection of damping coefficients to produce frequency-independent modal damping across both sets of modes.

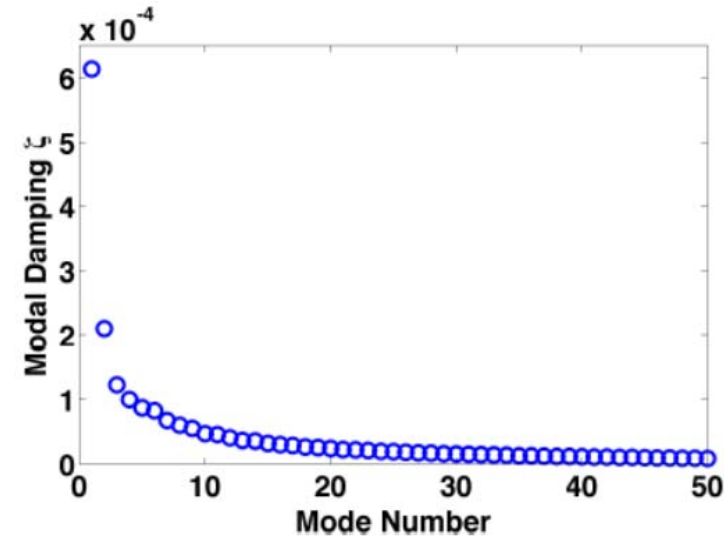

(a) Motion-based model.

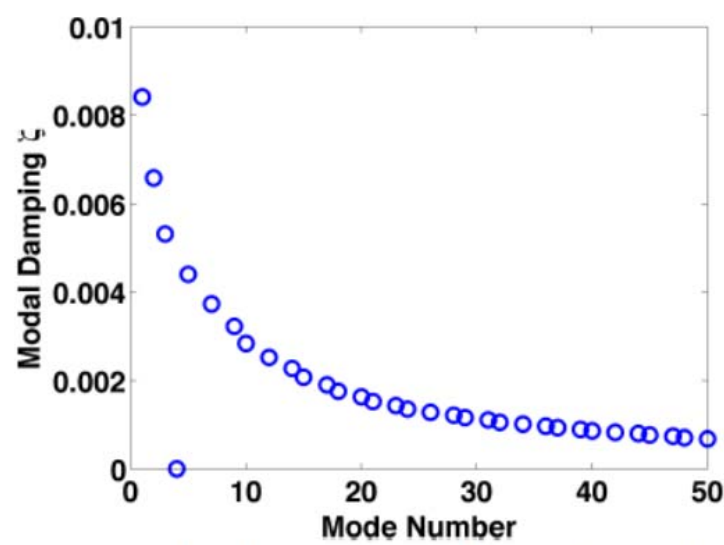

(c) Rotation-based (associated with centerline bending angle).

Figure 2 Modal damping for several viscous damping models with large shear deformation and rotary inertia effects.

\subsection{Mathematical Aside}

Previous research has indicated that so-called \square-root" damping results in modal damping that is independent of frequency [21]. This approach involves representing the governing equation of motion in terms of differential operators: 


$$
\mathcal{M} \ddot{\gamma}+\mathcal{C} \dot{\gamma}+\mathcal{K} \gamma=f
$$

where $\gamma$ includes the coordinate(s) describing the system configuration and fincludes the external load(s) acting on the system. A damping differential operator that is twice the square root of the product of the mass and stiffness differential operators can be scaled to produce a desired modal damping $\varsigma_{0}$ that is independent of frequency [6]:

$$
\mathcal{C}=2 \zeta_{0} \sqrt{\mathcal{K} \mathcal{M}}
$$

In general, the square root of these operators depends on the system boundary conditions; however, approximate results can be found that provide modal damping that is approximately constant, at least over a large range of mode numbers.

Comparing Equation (17) with Equation (3), the mass and stiffness operators for a system with constant properties are, in matrix form,

$$
[\mathcal{M}]=\left[\begin{array}{cc}
\rho A & 0 \\
0 & \rho I
\end{array}\right] \quad \text { and } \quad[\mathcal{K}]=-\left[\begin{array}{cc}
\kappa A G()^{\prime \prime} & -\kappa A G()^{\prime} \\
\kappa A G()^{\prime} & E I()^{\prime \prime}-\kappa A G
\end{array}\right]
$$

While the square root of the mass operator is straight-forward, the square root of the stiffness operator is much more involved. Yet even for the shear beam (in which the differential operators are scalars instead of matrices), this approach did not yield terms that were easily explained in terms of physical dissipative mechanisms. A series expansion of the square-root damping terms, however, did lead to viscous damping terms that had clear physical underpinnings and provided approximately frequency-independent modal damping. As such, a similar series expansion will be explored for the Timoshenko beam in terms of physical dissipative mechanisms.

$$
[\mathcal{K}]=\frac{\sqrt{\kappa A G}}{\sqrt{\left(1+\sqrt{\frac{E I}{\kappa A G}}\right)^{2}()^{\prime \prime}-()}}\left[\begin{array}{cc}
\left(1+\sqrt{\frac{E I}{\kappa A G}}\right)()^{\prime \prime} & -()^{\prime} \\
()^{\prime} & \left(\frac{E I}{\kappa A G}+\sqrt{\frac{E I}{\kappa A G}}()^{\prime \prime}-()\right)
\end{array}\right]
$$




\section{CONCLUSIONS}

Previous research developed viscous damping models that resulted in approximately "frequency-independent" modal damping for both Euler-Bernoulli and shear beams. This research extends those models to a Timoshenko beam and examines their behavior (as well as that of more common proportional damping models) when rotary inertia effects are significant. In that case, the rotation-based model associated with the temporal rate of change of the centerline bending angle ' provides modal damping that decreases with mode number, though to much less degree than that of typical motion-based (mass-proportional) models. Similarly, the rotation-based model associated with the temporal rate of change of the shear angle _ provides modal damping that increases with mode number, though to much less degree than that of typical strain-based (stiffness-proportional) models. 


\section{REFERENCES}

[1] Ardelean, E. V., Goodding, J. C., Coombs, D. M., Griffee, J. C., Babuska, V., Robertson III, L. M., and Lane, S. A., "Cable Effects Study: Tangents, Rat Holes, Dead Ends, and Valuable Results," Proceedings of the Fifty-First AIAA/ASME/ASCE/AHS/ASC Structures, Structural Dynamics, and Materials Conference, AIAA 2010-2806, Orlando, FL, 2010.

[2] Babuska, V., Coombs, D. M., Goodding, J. C., Ardelean, E. V., Robertson, L. M., and Lane, S. A., "Modeling and Experimental Validation of Space Structures with Wiring Harnesses," Journal of Spacecraft and Rockets, Vol. 47, No. 6, Nov.-Dec. 2010, pp. 1038-1052.

[3] Goodding, J. C., Ardelean, E. V., Babuska, V., Robertson III, L. M., and Lane, S. A., "Experimental Techniques and Structural Parameter Estimation Studies of Spacecraft Cables," Journal of Spacecraft and Rockets, Vol. 48, No. 6, Nov.-Dec. 2011, pp. 942-957.

[4] Coombs, D. M., Goodding, J. C., Babuska, V., Ardelean, E. V., Robertson, L. M., and Lane, S. A., "Dynamic Modeling and Experimental Validation of a Cable-Loaded Panel," Journal of Spacecraft and Rockets, Vol. 48, No. 6, Nov.-Dec. 2011, pp. 958-973.

[5] Lesieutre, G. A., "Frequency-Independent Modal Damping for Flexural Structures via a Viscous 'Geometric' Damping Model," Journal of Guidance, Control, and Dynamics, Vol. 33, No. 6, Nov.-Dec. 2010, pp. 1931-1935.

[6] Kauffman, J. L., Lesieutre, G. A., and Babuska, V., "Damping Models for Shear Beams with Applications to Spacecraft Wiring Harnesses," Proceedings of the Fifty-third AIAA/ASME/ASCE/AHS/ASC Structures, Structural Dynamics, and Materials Conference, AIAA-2012-1641, Honolulu, HI, April 2012, in review by Journal of Spacecraft and Rockets.

[7] Lunden, R. and Akesson, B., "Damped second-order Rayleigh-Timoshenko beam vibration in space - an exact complex dynamic member stiffness matrix," International Journal for Numerical Methods in Engineering, Vol. 19, No. 3, March 1983, pp. 431-449.

[8] MacBain, J. C. and Genin, J., "Energy dissipation of a vibrating Timoshenko beam considering support and material damping," International Journal of Mechanical Sciences, Vol. 17, No. 4, April 1975, pp. 255-265.

[9] Irie, T., Yamada, G., and Takahashi, I., "The steady state out-of-plane response of a Timoshenko curved beam with internal damping," Journal of Sound and Vibration, Vol. 71, No. 1, July 1980, pp. 145-156.

[10] Chen, Y.-H. and Sheu, J.-T., "Axially-loaded damped Timoshenko beam on viscoelastic foundation,” International Journal for Numerical Methods in Engineering, Vol. 36, No. 6, March 1993, pp. 1013-1027.

[11] Esmailzadeh, E. and Jalili, N., "Optimum Design of Vibration Absorbers for Structurally Damped Timoshenko Beams," Journal of Vibration and Acoustics, Vol. 120, No. 4, Oct. 1998, pp. 833-841.

[12] Meirovitch, L., Principles and Techniques of Vibrations, Prentice Hall, Upper Saddle River, NJ, 1997.

[13] Huang, T. C. and Huang, C. C., "Free Vibrations of Viscoelastic Timoshenko Beams," Journal of Applied Mechanics, Vol. 38, No. 2, June 1971, pp. 515-521.

[14] Soufyane, A. and Wehbe, A., "Uniform Stabilization for the Timoshenko Beam by a Locally Distributed Damping," Electronic Journal of Differential Equations, Vol. 2003, No. 29, March 2003, pp. 1-14.

[15] Munoz Rivera, J. E. and Racke, R., "Global Stability for Damped Timoshenko Systems," Discrete and Continuous Dynamical Systems, Vol. 9, No. 6, Nov. 2003, pp. 1625-1639. 
[16] Lee, H.-L. and Chang, W.-J., "Effects of Damping on the Vibration Frequency of Atomic Force Microscope Cantilevers Using the Timoshenko Beam Model," Japanese Journal of Applied Physics, Vol. 48, No. 6, June 2009, p. 065005.

[17] Banks, H. T. and Wang, Y., "Damping Modeling in Timoshenko Beams," Proceedings of the 1992 American Control Conference, IEEE, Chicago, IL, June 1992, pp. 2139-2143.

[18] Zhao, H. L., Liu, K. S., and Zhang, C. G., "Stability for the Timoshenko Beam System with Local Kelvin-Voigt Damping," Acta Mathematica Sinica, Vol. 21, No. 3, June 2005, pp. 655-666.

[19] Chen, W.-R., "Bending vibration of axially loaded Timoshenko beams with locally distributed Kelvin-Voigt damping," Journal of Sound and Vibration, Vol. 330, No. 13, June 2011, pp. 3040-3056.

[20] Friedman, Z. and Kosmatka, J. B., “An Improved Two-node Timoshenko Beam Finite Element," Computers \& Structures, Vol. 47, No. 3, 1993, pp. 473-481.

[21] Chen, G. and Russell, D. L., "A Mathematical Model for Linear Elastic Systems with Structural Damping," Quarterly of Applied Mathematics, Vol. 39, Jan. 1982, pp. 433-454. 


\section{DISTRIBUTION LIST}

DTIC/OCP

8725 John J. Kingman Rd, Suite 0944

Ft Belvoir, VA 22060-6218

$1 \mathrm{cy}$

AFRL/RVIL

Kirtland AFB, NM 87117-5776

2 cys

Official Record Copy

AFRL/RVSV/Derek Doyle

$1 \mathrm{cy}$

Approved for Public Release; distribution is unlimited. 
(This page intentionally left blank)

Approved for Public Release; distribution is unlimited. 